\title{
DE METGE A PETRARCA PASANDO POR BOCCACCIO
}

JULIA BUTTIÑÁ JiMÉNEZ

UNED

Recientemente he propuesto una visión unitaria de la producción de Bernat Metge, bajo la problemática inherente al pensamiento humanista, lo cual afecta sobre todo al Libre de Fortuna e Prudencia, considerado antes como una obra medievalizante'. También he planteado una relectura de Lo Somni, de la que desprendo en el humanista catalán una profunda actitud ética, ante-

1 «Una volta per les obres de Metge de la mà de Fortuna i de Prudencia», en Miscel.lània Jordi Carbonell V. 1993, pp. 45-70. Precede a éste: «Un nou nom per al vell del Llibre de Fortuna e Prudència", Boletín de la Real Academia de Buenas Letras de Barcelona XLII, 1989-90, pp. 221-226.

Aunque tenga que empezar remitiendo a mis propios artículos, ya que este se inserta en una línea de investigación, no debo demorar el manifestar el talante del presente: en primer lugar, incluye el reconocimiento fundamental de la crítica anterior, que con solidísima base filologica ha establecido el dr. Riquer y ha continuado la dra. Lola Badia. En segundo lugar, lo presento como un avance, como bien revelan muchos aspectos aquí sólo apuntados; por lo que, a pesar de que en el desarrollo del trabajo sigo un proceso que pretende reflejar el mundo de los números - ya que fue el razonamiento que seguí al advertir el aspecto aquí expuesto-, valga el comentario de Tirèsias en Lo Somni: «mas no és tothom arismètic». Por último, y como concluyo, quiero manifestarme a favor de la actual lectura semiótica, según la cual hay tantas interpretaciones posibles como lecturas, debido al carácter abierto de las obras, lo cual me ha animado a la presentación de esta revolucionaria lectura del gran humanista catalán. 
riormente puesta en entredicho ${ }^{2}$. Actitud que es acorde con la inquietud filosófica que manifiestan las fuentes de Dante y sobre todo de Llull $^{3}$.

Fijaremos aquí nuestra atención en la Història de Valter e Griselda, pieza que se ha valorado principalmente por la belleza y la novedad de su prosa, noble, precisa y de un equilibrio clásico, pues «supone algo importante: la instauración de una prosa artística de cuño nuevo, que intenta reproducir en la lengua romance unos primores estilísticos que sólo parecían propios del latín clásicon ${ }^{4}$. Es traducción de la carta latina de Petrarca dirigida a Boccaccio, incluida en Rerum Senilium (libro XVII, epístola 3), que traduce a su vez el último cuento del Decameron (Jornada X, novela 10).

El dr. Riquer nos la define, a la vez que se extraña de su selección por parte del notario barcelonés: «El contingut narratiu del Valter e Griselda és un conte ingènuament inversemblant $\mathrm{i}$ arbitrari, on la fidelitat conjugal és exemplaritzada a base de les dures i inhumanes proves amb què el Marquès de Saluça sotmet la paciència de la seva humil esposa. No passa d'ésser una 'novel.leta exemplar', de tipus medieval o de rondalla popular, que contrasta amb les narracions de caràcter realista, alegre i llicenciós que tant abunden al Decameron de Boccaccio. Val a dir que sorprèn que Bernat Metge s'abellís d'aquesta historieta». ${ }^{5}$ Más aún cuando el tema debía ser conocido, pues su fama nos la atestigua, quizá de un modo exagerado, el mismo Metge en Lo Somni:

«tant és notòria, que ja la reciten, per enganar les nits en les vetles e com filen en hivern entorn del foc» ${ }^{6}$.

Ahora bien, a la luz de las coordenadas que he expuesto al comienzo del trabajo, la elección de esta historieta por parte de Metge cobraría significado.

2 «Bernat Metge y su terrorifica amante (una relectura de Lo Somni)», Antipodas, La Trobe University (en prensa).

3 Aspecto que expongo en «El diálogo de Bernat Metge con Ramon Llull. (Dos nuevas fuentes tras Lo Somni)», V Congreso de la Asociación Hispánica de Literatura Medieval (Granada, 1993), y en «Metge, un bon lul.lista», presentado a Estudios Lulianos.

4 M. DE Riquer, Obras de Bernat Metge, Universidad de Barcelona, 1959, p. 48.

${ }^{5}$ Historia de la Literatura Catalana, II, Barcelona, ed. Ariel, 1964, p. 376.

- Obra completa de Bernat Metge, a cargo de L. BADIA i X. LAmuela, Barcelona, ed. Selecta, $3^{2}$ ed., 1983, p. 234. Citaremos por esta edición, que sigue la de Martín de Riquer citada. En esta última (o. cit. , p. 48) se anota la variante de dos manuscritos acerca de esta frase: «les velles com filen". 
Acompañan al relato dos cartas: lo precede una «lletra dedicatòria» y lo cierra una «lletra d'endreça» - redactadas con un estilo más solemne y complejo, distinto al llano del relato-, las cuales reproducimos como apéndice. En ambas hay una mención de Petrarca; en la primera dice que tiene «singular afecció» a sus obras, y en la última da una referencia lingüística en cuanto a su propia prosa, que en relación con la fuente considera "fort grossera». Y van dirigidas a Isabel de Guimerà, hija de Berenguer de Relat, tesorero de la reina Elionor, a la cual también sirvió Bernat Metge; esta dama de la corte había casado en 1372 con Gispert de Guimerà, señor de Ciutadilla.

En primer lugar, teniendo en cuenta a quien se dirige el relato y su temática -De insigni obedientia et fide uxoris, según la titula Petrarca-, se deduce que no puede incluir los trazos burlescos boccaccianos. En el Decameron, no sólo se manifiesta un desacuerdo entre los amigos oyentes del relato acerca del comportamiento de la pobre Griselda, sino que una chanza de Dioneo da a entender que se han reído con lo que interpretan una exageración, a pesar de que el hilo unitivo de ese día eran casos de conducta liberal o magnífica. Sin embargo, el matiz jocoso no se desprende en ningún momento del grave y sencillo relato de Metge, lo cual es lógico, pues al ir dirigida la obra a una mujer casada nos hallaríamos de otro modo ante una burla esperpéntica. Metge ni menta a Boccaccio; pero obviamente conocía su autoría, pues en sus epístolas aparecen comentarios de la carta que le dirigió Petrarca con su traducción.

Hay que tener en consideración, por otro lado, que las referencias a Petrarca, cuando su figura era conocida en la Corona de Aragón ${ }^{7}$ y cuando en la Cancillería se escribía ya según el modelo ciceroniano, pueden interpretarse como algo más que una manifestación de admiración estilística. Además, añade Metge en sus comentarios epistolares que tan solemne poeta «viurà perpetualment en lo món per fama e per los insignes llibres que ha fets a nostra instrucció», juicio que parece exceder del comentario lingüístico ${ }^{8}$. Es sabido que la alineación con Petrarca implica una manifestación cultural, pero en un ambiente en que se daba de hecho cierta sensibilidad al humanismo hay que indagar acerca del alcance de este impacto y si además vehiculaba un contenido moral. Para descifrar algo al respecto hay que comenzar por contrastar las dos primeras Griseldas, la de Boccaccio y la de Petrarca.

7 Otro escribano de Joan I, Pere Pont, en 1386 o 1387, o sea poco antes de esta traducción de Metge que suele datarse hacia 1388, hacía también un elogio de Petrarca, que es el primero realizado en nuestra Península (véase la edición citada del dr. RiQuer, pp. 49-51).

${ }^{8} \mathrm{El} \mathrm{dr}$. Riquer ha destacado que Metge no se refiere al Petrarca italiano sino al de las poesías latinas y los tratados morales (véase su edición ya citada, p. 49). 
El análisis comparado que de ambos textos efectúa María Hernández Esteban revela matices muy interesantes, principalmente acerca de la mayor caracterización humana de los personajes, por parte de la versión petrarquesca. Concluye que en la explicación que Petrarca añade al final de su relato, análoga en posición a la de Dioneo, encierra su réplica al certaldés. «Pero a diferencia de la parodia, o de la sátira, que adoptan una directriz claramente descendente, aquí se trata de proyectar el texto hacia arriba, hacia una dimensión más elevada. También él, como Boccaccio, reconoce que la conducta de Griselda resulta difícil de imitar por las señoras de su tiempo, pero desde luego que no sólo no descarta sino que subraya el valor ejemplar del relato, proyectando lo individual de su protagonista al nivel universal de la conducta humana, de toda la humanidad»?.

Asimismo Metge, no sólo dice en la epístola proemial que la historia se funda «en virtuts de paciència, obediència e amor conjugal», carácter ejemplar que mantiene en la epilogal, sino que en ésta, situada paralelamente a la petrarquesca al final de su versión, da la misma referencia a mujeres virtuosas de la Antiguiedad que diera Petrarca. Sólo ya en función al paralelismo cuesta desprender al relato de Metge de una intencionalidad de ejemplo similar a la de Petrarca ${ }^{10}$.

Aquellas virtudes son además de realce muy sintomático cuando Petrarca había acentuado en la presentación de Griselda su belleza moral, perfilando los rasgos humanos del personaje, en función, por ejemplo, de la dedicación al trabajo, la obediencia o el amor filial. Progresivamente destacará su excepcionalidad hasta culminar «con esa cláusula casi stilnovista (...) que apunta a la función mediadora de la mujer para el hombre y que abre el proceso de proyección al plano espiritual que el autor establece ya al final, fuera de los límites del relato» ${ }^{11}$. Sin embargo, apreciamos algún matiz diferenciador entre Metge y Petrarca, que trataremos posteriormente.

En cuanto al relato boccacciano cabe destacar aquí que, en cambio, «en boca de Dioneo, resulta ser explícitamente un caso de relato anti-ejemplar, por la actuación de Gualtieri; e implícitamente es un modelo de conducta femenina negativa, pues la pasividad de Griselda no sintoniza con la perspectiva dominante que se defiende en el libro» ${ }^{12}$.

9 «Lecturas del relato de Griselda: Decameron X, 10 y Seniles, XVII, 3*, Rivista di Letteratura Italiana IX,3, 1991, p. 399.

10 Ello se ratifica además desde Lo Somni: la cita del valor de la humilde Griselda viene a continuación de la relación de las prestigiosas y deslumbrantes heroínas clásicas.

11 \&Lecturas del relato de Griselda..»., art. cit., p. 395.

12 Id., tb., p. 380. 
Hay otro aspecto que deriva esta investigadora y es que Petrarca «logra borrar algunas de las ambigüedades del texto boccacciano, dándole una dimensión con la que la tradición podrá sintonizar plenamente; de ahí, entre otras razones, la clave de la espectacular difusión artística y literaria de esta "lectura" petrarquesca» ${ }^{13}$. Es evidente que su relato, casi medieval por el talante, era sumamente conciliador con la vieja mentalidad; no se rompe con las viejas costumbres, pero se interpretan de otra manera. Cabe preguntarse si también en ello Metge seguía a Petrarca, sea como manifestación condicionada $o$ auténtica.

Si decimos condicionada es a causa de la difícil situación en que se hallaba al escribir esta obrita, según confiesa «per envejosos contra justícia maltractat», dato que ha provocado que su redacción se relacionara con el proceso de 1388 en el que parece que estuvo implicado ${ }^{14}$. Es decir, pudiera ser que Metge estuviera recurriendo a sus amistades próximas al ambiente hostil cortesano y aclarara que su pensamiento, a pesar de seguir la nueva corriente, no rompía con la tradición. O pudiera ser que en aquel punto, momento y por una sincera amistad, estuviera manifestando una actitud concreta personal a favor de la virtud, conciliadora por cierto, y en que coincidía con Petrarca. $O$ posiblemente ambas cosas a la vez, pues algo similar ocurre en su gran diálogo, en que expone lo que le beneficia pero sin privar de su intimidad a los lectores que podían entenderlo.

Asimismo, en el Libre de Fortuna e Prudència, ofrece una lectura humanista de rotundo rechazo de la mentalidad tradicional, cuando hasta la actualidad se había entendido como una obra de línea medievalizante. E igualmente en Lo Somni presenta también esta ambivalencia, en una coyuntura muy arriesgada, en la que sólo deberían traducir la ruptura los amigos más allegados, pues el primer lector iba a ser el rey Martín I, de quien dependía su comprometidísimo futuro tras el sonado y arriesgado proceso de 1396, que le afectó tan directamente.

Precisamente en esta última obra la repulsa la efectúa a través también de una obra de Boccaccio: en el libro IV de este diálogo el humanista catalán se opone abiertamente a los argumentos misóginos del Corbaccio expuestos en el III. Ello es importante, pues si Petrarca había iniciado una réplica con cierto contenido ético, nuestro autor enmienda la plana al certaldés por dos veces, lo cual supone una sintomática reincidencia. En ambas ocasiones muestra su alto

13 Id., $t$ b., p. 399.

14 Véase Histdria de la Literatura Catalana, o. cit. , pp. 370-373. 
concepto de la virtud, que contrapone a la moral vulgar y misógina predominante en su tiempo ${ }^{15}$.

La investigadora que venimos siguiendo advierte asimismo la dimensión espiritual que añade Petrarca: así, con la inclusión de referencias a la muerte, ausentes en Boccaccio, o en el concepto de nobleza de sangre que critica éste y que en la versión de Petrarca se resuelve en asunto dependiente de la voluntad divina. Por último, y en relación nuevamente con la explicación final petrarquiana, añade un rasgo a la aportación de Petrarca sobre el relato de Boccaccio, la referencia religiosa: «la ecuación analógica que establece, "Griselda se comportó con Gualtieri como el hombre debería comportarse con Dios", proyecta su texto hacia esa dimensión transcendental que tan unida camina a la dimensión humana de su producción ${ }^{16}$.

Perspectiva que en relación con Metge podría dar lugar a muy largas consideraciones que excederían los límites de este trabajo, y que si sólo apuntamos y en una breve enumeración es porque puede ilustrar posteriores observaciones:

1) en la mayoría de sus obras se puede apreciar, con mayor o menor incidencia e imbricación, una doble vertiente existencial-ética, y en la misma epístola final, al atacar a los que privan del valor ejemplar al relato, se refiere a ellos como «menyscreents e viciosos», lo que nos ofrece una dimensión religiosa y moral;

2) parece obvio que en el último párrafo, en que se reconoce injustamente maltratado hay una asimilación de él mismo, Metge, al caso que ha traducido, el de la víctima Griselda;

3) lo que nos plantea la cuestión, que no podemos dejar de abrir dada la precisión del notario, de hasta qué punto le afecta el salto a lo divino que da Petrarca, teniendo en cuenta que él alega a la divinidad - también paralelamente - al solicitar las plegarias de madona Isabel.

4) Y por lo tanto, que su propia inserción podía ser otro calco, una prolongación o continuación (Metge=hombre) de la abstracción generali-

15 Respecto al talante humanista de renovación comenta Francisco Rico que si Petrarca califica de basura el periodo anterior entre la Antigüedad y la renovación, «la solución habrá de ser también una limpieza total, un barrido que no olvide ni un rincón, de la lengua y la literatura a las costumbres y la vida diaria». (El sueño del humanismo. De Petrarca a Erasmo, Alianza Universidad, Madrid, 1993, p. 23).

${ }^{16}$ Lecturas del relato de Griselda ..., art. cit., p. 398. 
zadora propia de Petrarca, al igual que éste había efectuado la similitud de actitudes Griselda=ser humano.

Si los puntos 1 y 2 se imponen por sí mismos, los 3 y 4 son un planteamiento hipotético. Ahora bien, aunque - como hemos dicho- nos referiremos a los matices diferenciadores con posterioridad, podemos desprender hasta ahora que su expresión de vinculación al «poeta laureat» encierra una muy profunda adhesión. Que, si bien están por especificar muchos matices, tiene repercusión en el ámbito moral y quizás en el existencial.

Esta actitud se constata a través de un contraste literario que efectuamos como una simple operación aritmética: Metge añade a Boccaccio lo mismo que Petrarca al tratar al certaldés, lo cual nos iguala ambos extremos; es decir, ambos emplean la misma tónica en su tratamiento. En primer lugar, se ratifica claramente en Lo Somni, tanto por la ascensión a que ha hecho referencia María'Hernández como por el establecimiento de la ejemplaridad.

En el gran diálogo Metge dedica los dos primeros libros al tema de la vida futura, con resonancias de los mayores pensadores de la humanidad (Platón, Cicerón, santo Tomás...), y los dos últimos al tema del misoginismo. Lo cual, cuando hay una perfecta ilación y no se da en absoluto una mutación formal en los dos últimos libros, a pesar de ser las fuentes de tan distinta procedencia, suponía un desnivel difícil de explicar en obra de tanta altura. «Si hi ha un cert aparent desequilibri entre la trascendència dels temes desenvolupats a la primera part de l'obra i la trivialitat dels de la segona, el valor literari de la prosa es manté constant» ${ }^{17}$. Por otro lado, la íntima vinculación entre los libros se hace patente en detalles como el emplear las mismas expresiones aplicadas en uno y otro bloque.

Propongo, pues, que al tratar algo considerado vulgar como un tema noble y de relieve está realizando una ascensión similar a la que realizaba Petrarca con Griselda, lo cual no es difícil de admitir teniendo en cuenta que precisamente también Metge recurría a una obra de Boccaccio, pues ya hemos dicho que los dos últimos libros de Lo Somni giran alrededor del Corbaccio, al que rechazan rotundamente. Es más el dr. Riquer nos da un dato muy elocuente al respecto: «el Boccaccio del Corbaccio es refutado con pasajes tomados principalmente de una epístola de Petrarca y con recuerdos del De claris mulieribus del propio Boccaccio. Es sin duda intencionado que el Boccaccio en italiano sea refutado con el Boccaccio en latín, pero aún lo es más que Boccaccio sea

17 De la introducción a la edición que seguimos, p. 37. 
refutado por Petrarca» ${ }^{18}$. Cabría esperar a un cotejo similar al realizado con las Griseldas por María Hernández, pero de antemano se nos hace patente que en su repulsa a Boccaccio, Metge se identifica con Petrarca.

Este enfoque no sólo nos muestra la lógica proporción del gran diálogo, sino además el talante moral del autor. Por la alta valoración de una virtud, la amorosa, que juzgaría maltratada en su tiempo. E incluso, si tenemos en cuenta el caso de Griselda, por encumbrar un caso de tan poca relevancia, y -aunque la expresión parezca actual- por la reivindicación de la dignidad de la mujer ${ }^{19}$.

El segundo punto que nos afirma la similitud de talante respecto a Petrarca en el tratamiento de Boccaccio es el ejemplo. Griselda era aupada a la categoría ejemplar. En cierto modo como Metge, que en Lo Somni recurrirá a un personaje del mundo clásico, ya que en este diálogo oponía la actitud ejemplar de Orfeu al concepto despreciativo y ridiculizador que del amor encarna Tirèsias:

«- $\mathrm{O}$ Oh, com ést foll -respòs ell- e de lleugera creença! No saps què són dones tan bé com jo. ¿Són açò paraules d'home ab sana pensa? ¿Són açò paraules covinent a la tua edat? ¿Són açò paraules d'hom qui am ciència e haja llegit tant com tu? Lleixa semblants coses a hòmens ociosos, vans e il.literats, car lo teu enginy no es deu distribuir en amor: pus altes coses li sonn llegudes» ${ }^{20}$.

Al tratarse de otra obra no nos compete en rigor atender al ejercicio de contraponer ambas figuras y lo que representan. Baste destacar que uno se dedica a maldecir a las mujeres y a prevenir a Metge de los horrores de su amante, en paralelo con el Corbaccio y en consonancia con la figura mitológica que separó a dos serpientes apareadas. Es decir, es un concepto del amor que genera odio, en oposición al de Orfeu. Pues éste, cuya vida trata con cierta libertad

18 Sigue: «En cierto modo es la misma actitud de 1388, cuando Bernat Metge traduce el Griseldis afirmando que es obra de Petrarca y se calla lo que muy bien sabía, que es una traducción de una narración escrita en italiano por Boccaccion. ( Boccaccio en la literatura catalana medieval», Filología Moderna, 55, 1975, p. 461).

La epístola a que se refiere es la 8 del libro XXI de Familiarium rerum, dirigida a la emperatriz Ana, en la que Petrarca escribe uno de los más bellos textos acerca del valor de la mujer.

19 Todo ello se está considerando aquí independientemente de su relación con las líneas del debate acerca de la misoginia, aspecto cuya atención excedería de nuestros objetivos.

20 Obra completa, p. 202. 
y constituye «no tan sólo uno de los fragmentos de más bella prosa de Lo Som$n i$, sino de toda la obra de Bernat Metge» ${ }^{21}$, relata cómo gracias a su música "aquells qui naturalment són enemics estaven ensems», y cómo a pesar de morir a manos de las bacantes, nunca cejo en su conmovedor amor por Eurídice ${ }^{22}$.

Es más, su admiración por el concepto de amor bebido en Ovidio lo hace manifiesto en esta misma epístola prologal. Aquella ejemplaridad no se había destacado anteriormente porque en la obra -escrita en un momento comprometido para su autor, tanto como supone el haber estado recientemente encarcelado, y que el primer lector sería el rey y el entorno cortesano contrarios a la nueva corriente de pensamiento-, se dice que Orfeu y Tirèsias representan la afición a la música, la caza y la astrología. Lo cual a todas luces, al alegarse como purga de las tendencias pecaminosas del rey fallecido, es suficiente para su aparición. La habilidad del autor que escribía para distintas audiencias -además de la enunciada, sabemos de su entorno de amistades, a las que dedica la Medecina, y la posteridad, a la que confiesa como móvil de Lo Somni, en nueva afinidad con Petrarca- había de ser extrema.

Vamos a establecer un último contacto significativo de nuestra Griselda con otra traducción de Metge por lo que tiene de coincidencia en actitudes morales. A la obrita Ovidi enamorat no se le había dado mayor trascendencia. Pero no podemos dejar de dársela desde este ángulo, pues, dada la personalidad del secretario real y lo que significaba, sus traducciones no debían circular ni interpretarse como meros ejercicios estilísticos. Es más, sus declaraciones literarias serían compromisos auténticos, puesto que ejercía como alto cargo real implicado en asuntos turbulentos al ciento por ciento.

Como dice el dr. Riquer, el «Ovidi enamorat, que segurament també es conegué amb el títol de La velletona, és una traducció en prosa del llibre segon d'un poema llatí en hexàmetres, De vetula, que hom creia que era obra

21 De la edición de M. de Riquer, p. 159.

22 Sin embargo habría que hacer un minucioso seguimiento comparativo, así como de las variaciones respecto al relato ovidiano. Destaco, por ejemplo, que el instrumento musical de Orfeo en Las Metamorfosis es la lira y en Lo Somni, la rota 'la cítara, o lira de mayor tamaño'. Al respecto observa Coromines en el Diccionari Etimoldgic i Complementari de la Llengua Catalana: «Prou es recordava Bernat Metge, secretari del rei Joan I, de les sessions literàries, presidides per la reina Violant de Bar, en què el rei en persona, cantava, acompanyant-se amb la rota, ballades, virolais i rondeaux, compostos per ell en francès...» (vol. VII, ed. Curial, Barcelona, 1987, p. 492). Podría, pues, haber una cierta asimilación Orfeu-Joan I, el gran amigo recientemente fallecido, con cuyo espíritu dialoga en el libro I, y partícipe en la actitud humanista. 
d'Ovidi, atribució que no enganyà un home tan bon coneixedor dels clàssics com fou Petrarca» ${ }^{23}$.

Dice también que «Bernat Metge estaba convencido de que el poema era de Ovidio, ya que en un momento determinado hace que el protagonista de la narración sea llamado por una criada ' $O$ benaventurat Ovidi!', siendo así que en el texto original correspondiente no aparece ningún nombre propio 24 . Nos interesa especialmente el título que aparece en el único manuscrito que nos la ha transmitido: Com se comportà Ovidi essent enamorat ${ }^{25}$, porque alude a un comportamiento. Lo cual nos hace concederle atención en función a la posible perspectiva ética y a su vez nos puede indicar que el tema en sí - al margen de que le engañara o no su autoría- le convenía o interesaba.

En los últimos párrafos del pseudo-ovidiano relato, con los que concluye a modo de reflexión final, el narrador, con talante casi grotesco de resignado, pues es víctima de engaño redoblado, hace manifiesto que resuelve quedarse junto a la vieja que no sólo le había causado un fuerte desencanto amoroso en su juventud sino que además le ha vaciado de dinero. A pesar de cierta pretensión de ser justo en su actitud, con una postura de humanidad y en función a la misma vejez, al tiempo que han pasado juntos y al afecto, acepta sus inconvenientes, con clara alusión a los sexuales, que eran nucleares en la obra y le otorgaban un matiz abiertamente subido de tono y divertido.

Observemos que la moraleja de resignación aparece también en otras obras de Metge: en el Libre de Fortuna e Prudencia ya desde el comienzo en que sufre la burla del viejo villano y en la que adopta un contenido existencial, y en Lo Somni, donde acepta el ataque y vituperio de Tirèsias a su amante, y a pesar de ello asume sus faltas y la defiende. Y sobre todo en este relato de Griselda, pues todo él incluye una moral de aceptación llevada al extremo.

Esta actitud de resignación ante el engaño es acorde con el característico gesto de Metge de hombre inocente e indefenso, que tanto contrasta a la vista de su hábil simulación y sagaz inteligencia, y que se interpretaba como doblez. Pero a la vista de nuestra exposición, sin restarle un ápice de aquellos rasgos, el gesto de aceptación se muestra como una actitud fundamentada.

23 Historia de la Literatura Catalana, o. cit. , p. 369.

24 Vease la edición del dr. Riquer, p. 33 y 111.

25 De todos modos en el primer pasaje citado el dr. Riquer explica las incidencias respecto al título, que no puede adjudicarse con seguridad a Metge. 
Ante todo hay que abrir la pregunta acerca de qué tipo de resignación se trata:

1) de la ética tal como aparece en sus escritos o de la ética que podían captar los que entendían su interioridad.

2) o bien de la religiosa, que Petrarca en el relato que ambos traducen abre como sugerencia.

Y si la primera ética, la aparente, es a todas luces literaria, pues por mucho que lo mantenga el adivino Tirèsias nadie ha postulado que los terribles vituperios se dirigieran a una verdadera amante del notable funcionario, la segunda se nos abre exigentemente al análisis, pues se funda en comportamientos de resignación extrema que rememoran el petrasquesco ante la Fortuna buena o mala y la concepción de la vida como una prueba, que el admirado poeta mantuvo hasta el final ${ }^{26}$.

En cuanto al segundo tipo de resignación, es un interrogante posiblemente sin solución, que abre un abismo que excede nuevamente con creces la propuesta de reflexión que aquí hemos iniciado ${ }^{27}$.

Insistimos, sin embargo, en el enfoque ético, a pesar de constarnos la ficcionalidad literaria y de no constarnos hasta qué punto - a pesar de su identificación con Petrarca- en el caso de Griselda realizaba Metge la ascensión del ejemplo hacia una dimensión universal o se quedaba en un plano individual, en un consejo a Isabel de Guimerà. Nuestra insistencia se basa en dos motivos: porque el giro del Petrarca maduro hacia las actitudes vitales se corresponde con la dinámica de transformación propia de los grandes humanistas y no podía ser ajeno a un admirador de Petrarca como Metge. Y porque podemos establecer un enlace entre la moral que critica aquí - atacando a sus seguidores- y la que condena en otras obras, como el Sermó y Lo Somni, al identificarse todas ellas con la tradicional propia de su ambiente.

Metge contrapone a ésta una moral de mayor exigencia, natural y con modelos paganos, a la vez que manifiesta hacia aquella, la propia de su entorno, un craso desprecio. Como muestra que ruegue a su buena amiga:

26 En la última carta a su hermano (Rerum Senilium XV, 5) da gracias a Dios por los bienes y por los males, pues no concibe éstos como castigo sino como una continua prueba.

27 Pero que hay que tener en consideracion: tras la ecuacion Metge=hombre apuntada se trasluce otra relación de consecuencia, Valter=divinidad, en la cual encaja muy adecuadamente la sensación de victimismo, habitual en sus obras, y donde la existencia tiene una connotación de engaño en cuanto la razón no lleva al plano trascendente. Lo cual exige una ética férrea. Ello situaría a Metge en una línea de pensamiento próxima a corrientes modernas, cercanas al existencialismo, y justificaría más aún la falta de transparencia hacia sus congéneres. 
"que la dita història vullats creure així com és posada, car així fo allà com dessús és dit, jatsia que alguns menyscreents e viciosos diguen que impossible és que dona del món pogués haver la paciència e constància que de Griselda és escrita.»

O sea que la virtud llevada al extremo, que para algunos puede parecer algo jocoso, es no sólo algo válido como ejemplo abstracto, como dice Petrarca, sino real. Y él se sitúa en un plano opuesto al del mundillo que se ríe o lo niega, y asume casos literarios en primera persona - bajo el yo literario en su gran diálogo y quizá también bajo el nombre de Ovidio-, en los que la virtud - llámese fidelidad sentimental o amor humano, tanto en Griselda, el Ovidi o en Lo Somni-, es una virtud extrema. A prueba de burlas y sin mermas; una virtud que genera virtud y sin conatos de malicia. Con lo que se giran los cánones de la moral establecida en su época y se retorna a un cristianismo primigenio.

Observemos ahora que Metge, al arremeter contra los que niegan el valor ejemplar porque a ellos les parece difícil, ha ido más allá de Petrarca. Pues éste acuerda con Boccaccio en la dificultad de aplicar tales conductas en su tiempo («Hanc historiam stilo nunc alio retexere visum fuit, non tam ideo, ut matronas nostri temporis ad imitandam huius uxoris patientiam, que michi vix imitabilis videtur, quam ut legentes ad imitandam saltem femine constantiam excitarem»). Ahí sí que puede establecerse un matiz diferenciador. Lo cual no quiere decir que desacuerde con él sino, al contrario, que va más allá o acentúa su postura ${ }^{28}$.

Todo ello es sumamente arriesgado cuando nos hallamos ante un escritor cuya integridad ética se ha puesto en duda, en su tiempo y en el nuestro. Como puede parecer complejo que exponga el mismo talante resignado ${ }^{29}$ tanto ante casos medievalizantes, de sabor casi hagiográfico, como sobre modelos

28 Metge excluye la aplicación religiosa directa y llana de Petrarca pues, aunque con igual resultado ético, eran muy otros y problemáticos los planteamientos donde desembocaba su racionalismo. Pero según el planteamiento hipotético que apuntamos, cabe preguntarse si el vuelco a lo divino que el caso de Griselda había sugerido en Petrarca («ut quod hec viro suo prestitit, hoc prestare Deo nostro audeant») podía haberlo trasladado también a un plano existencial -superior, no religioso - en cuanto él mismo podía afirmarse como una muestra real desde el punto de vista ético. Y ello nos remite al Libre de Fortuna e Prudencia.

29 Posteriormente a la elaboración de este trabajo y desde otro flanco de investigación, me ratifico en esta propuesta (aparecerá en la Miscel-lània Germà Colon:: «Jo comens allà on deig, car Job no fou jueu, ans fou ben gentil»). 
ovidianos, bajo unos esquemas aparentemente inmorales; si bien tienen en común un concepto de virtud heroica.

Pero nos abre la posibilidad de leer sus libros con los ojos de los amigos que se reían con sus ingeniosísimas ironías, a la vez que entenderían con total seriedad los pasajes que no admiten bromas o se prestan a una gran profundidad. Como puede inclinar a pensar que lo era el que tratamos cuando a una de sus tres hijas puso el nombre de Griselda. 


\section{APÉNDICE}

\section{Letra dedicatoria}

A la molt honorable e honesta senyora madona Isabel de Guimerà, Bernat Metge, salut e reverència subjectiva.

A mi, encercant entre los llibres dels fildsofs e poetes alguna cosa ab la qual pogués complaure a les dones virtuoses, ocorrec l'altre dia una historia la qual recita Petrarca, poeta laureat, en les obres del qual jo he singular afeccio. E com la dita historia sia fundada en virtuts de paciència, obediencia e amor conjugal, e a mi sia cert que, entre les altres virtuts, vós, senyora, siats dotada d'aquestes singularment, per ço he deliberat d'arromançar la dita història, e de trametre-la-us perquè vós e les altres dones virtuoses prenats eximpli de les coses en aquella contengudes (no per tant que jo em pens que vosaltres freturets d'aquesta doctrina, car sens ella sóts assats pacients e virtuoses, mas per ço que oints la present historia, siats pus ardents en seguir les dites virtuts, car diu lo mestre d'amor, Ovidi, en les obres del qual en temps que jo amava me solia molt delitar, que al cavall lleuger quan corre no li nou si hom li dóna alguna esperonada), suplicant-vos que la present historia vullats benignament oir, e en les adversitats, les quals algú en aquesta present vida no pot esquivar, con lloc serà, ben remembrar d'aquella, per ço que mills e pus pacientment puixats aquelles soferir, de les quals Déu vos vulla preservar per sa mercè.

\section{Lletra d'endreça}

La present historia, senyora molt graciosa, he arromançada com pus pla he poscut e sabut; la qual, en esgordament del llatí en què Petrarca la posà, és fort grossera. Mas jo, imaginant que complauria a rós, no he recusat de demostrar la mia grossera inepti- 
tud e atreviment gran que he haüt com he gosat parlar aprés tan solemne poeta com aquell és, lo qual viurà perpetualment en lo món per fama e per los insignes llibres que ha fets a nostra instruccio, suplicant-vos, senyora, que la dita historia vullats creure així com és posada, car així fo allà com dessús és dit, jatsia que alguns menyscreents e viciosos diguen que impossible és que dona del món pogués haver la paciència e constància que de Griselda és escrita. Als quals hom poria ben respondre que ells tenen aquella opinió per ço com imaginen que açò qui a ells és difícil sia als altres impossible. Car moltes dones són estades qui han haüda meravellosa paciència, constància e amor conjugal, així com fo Porcia, filla de Cató, qui es matà com sabé que Varró, marit seu, era mort, e Hipsicratea, regina, qui volc anar per lo món així com exellada ab Mitridates, marit seu, e moltes altres coses les quals de present no em cur de recitar.

Suplic-vos, encara, senyora, que mi, per envejosos contra justícia maltractat, vullats haver per recomanat en vostres devotes oracions; car Nostre Senyor ha mès en vós tant de bé, e vós que en sabets tan virtuosament usar, que no em pens que denant Ell poguéssets trobar repulsa de res que li demanàssets. 